\title{
Art, Labels and Wine: you can't judge a book by its cover
}

\author{
Shaun R. McCann ${ }^{1}$ \\ Received: 14 March 2019 / Accepted: 14 March 2019 / Published online: 5 April 2019 \\ (c) Springer Nature Limited 2019
}

"You Can't Judge a Book by the Cover" is a 1962 song by rock and roll pioneer Bo Diddley (1928-2008). Written by Willie Dixon, the song was one of Diddley's last record chart hits.

Well, I'm not so sure. Why do designers put pictures of voluptuous scantily clad females on the cover of books? I presume it increases the possibility of sales. The late John Goldman had an ingenious idea when he decided to put art images on the cover of the journal: Bone Marrow Transplantation (BMT) [1]. He had a degree in classics from Oxford and I don't know whether he was thinking of refuting CP Snow's observation that the world of the arts and the sciences would never intersect (on 7 May 1959, CP Snow mounted the podium in the Senate House in Cambridge to deliver that year's Rede Lecture. The title was 'The Two Cultures and the Scientific Revolution' and his theme was the dangerously wide gap that had opened up between scientists and "literary intellectuals."). With John as editor and Robert Peter 'Bob' Gale as co-editor, John decided to link the Arts and Sciences in BMT. The first piece of art to appear on the cover in 1989 was a copy of Lamelles by Sonia Delaunay (1885-1997), which hung in his home in Notting Hill, London. At the annual meeting of the EBMT in Frankfurt John approached my wife (Dr Brenda Moore-McCann, a physician and art historian) and asked her to choose an artwork for the cover of BMT. She produced a photograph of an artwork by the pioneering conceptual artist Patrick Ireland a.k.a. Brian O' Doherty, about whom she was writing a book, and he agreed to put it on the cover (Fig. 1).

Some wine makers also put art works on the labels of their wine bottles. The most widely known labels were commissioned by Baron Philippe de Rothschild. Philippe Julian, in 1945, designed labels for Mouton Rothschild

Shaun R. McCann

shaunrmccann@gmail.com

1 Haematology Emeritus, Trinity College, University of Dublin, Dublin, Ireland

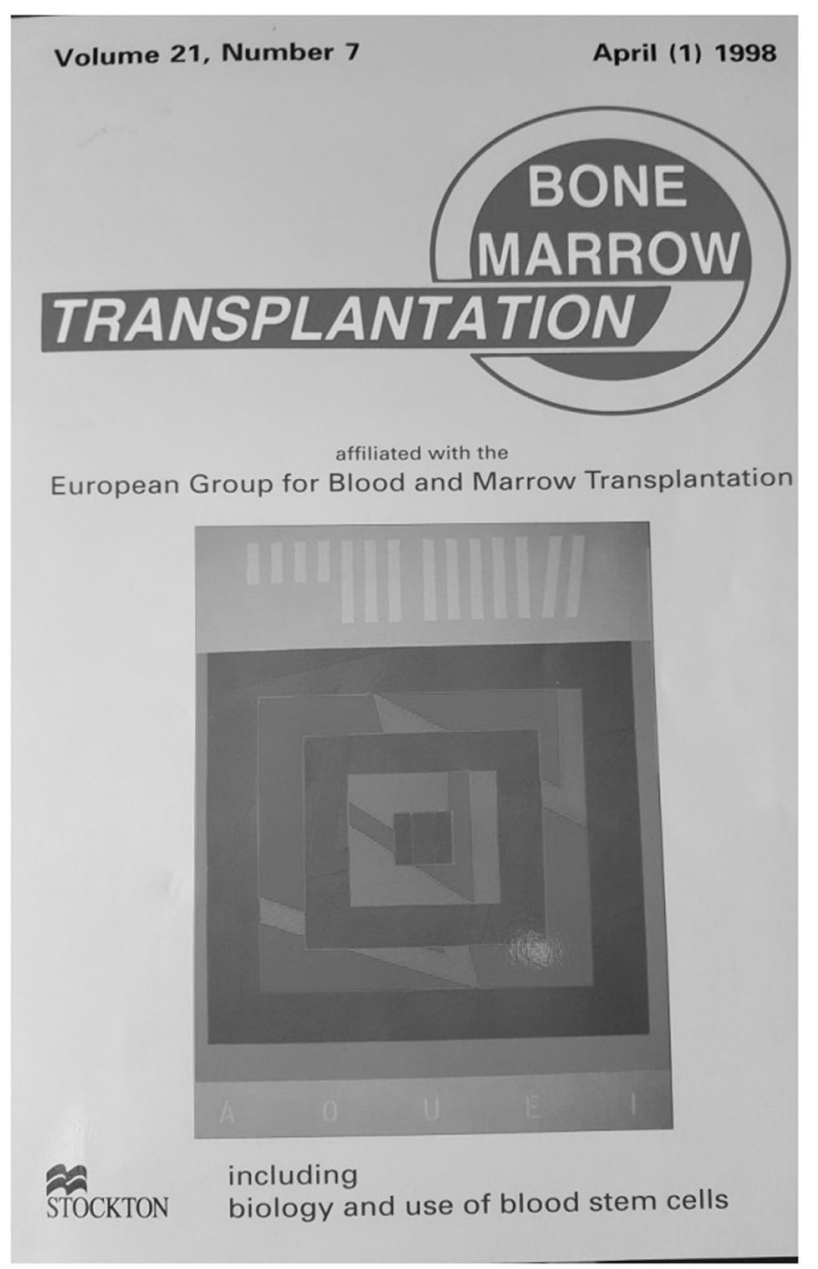

Fig. 1 Cover of the journal Bone Marrow Transplantation 1998. The Song of the Vowels (1996) Patrick Ireland. This panel is one of nine painted onto the walls of the Sirius Arts Centre, Ireland, in a conceptual artwork entitled The Ogham Cycle, One Here Now. Although it can be enjoyed as a brightly coloured abstract painting, an exploration of the role of language in shaping identity underlies the work. Vowels, the primal elements of language, are visually fused in the languages that have affected Irish identity over time- the ancient Celtic language Ogham (c 400 AD), Gaelic, and English. The upper register spells the word 'cuig' (the Gaelic for five) in Ogham. In the centre, each square represents one of the vowels in Ogham. The lower register gives the vowels in the Roman alphabet. Patrick Ireland qualified as a doctor in Dublin. This work resulted from his residency at the Sirius Arts Centre. Brenda Moore-McCann, MB. BA. $\mathrm{PhD}$. 
made from grapes harvested in the dying days of World War II, which depicted a simple V. Nineteen forty-five was a fabulous year for Bordeaux: hot and dry and characterised by wines of exceptional concentration and longevity [2]. Since then, artists including David Hockney, Marc Chagall, Joan Miró, Jeff Koons, Francis Bacon, Jean Cocteau, Andy Warhol (Fig. 2), and Lucien Freud, among others, have been designing labels for the first growth wine from Château Mouton Rothschild.

Sometimes there are problems with labels in the United States as when Balthus' drawing of a female nude was banned in 1993 for being 'pornographic', so the labels for wine exported to America had to be blank! When I visited the vineyard 'Nittardi' near the village of Castellina in

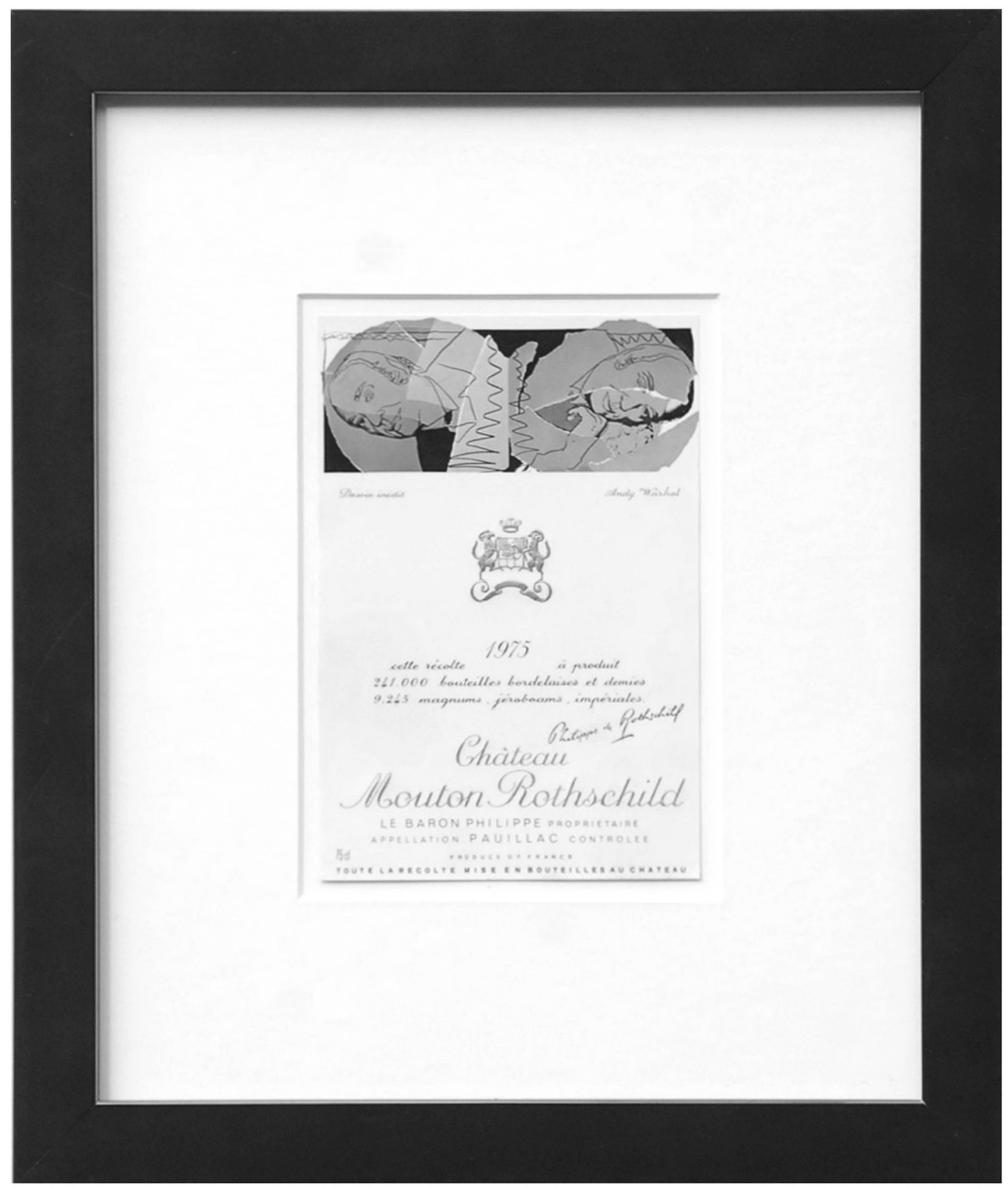

Fig. 2 Wine label for a 1975 bottle of Mouton Rothschild by Andy Warhol 


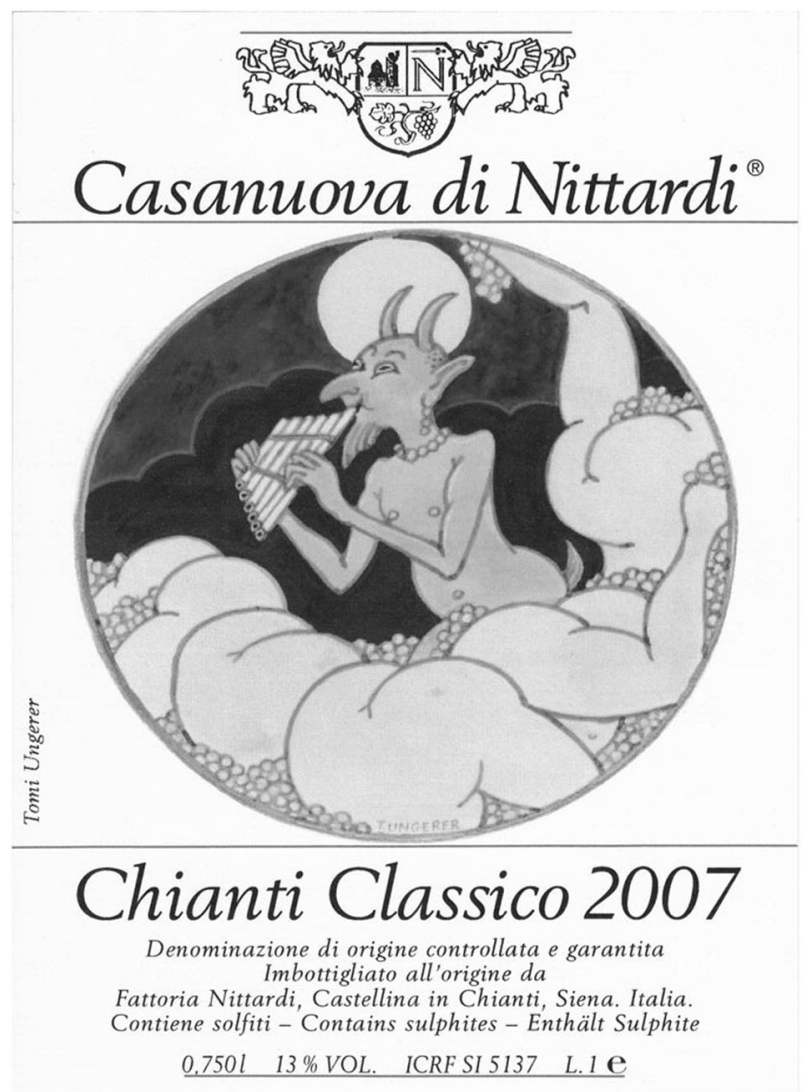

Fig. 3 Wine label from Fattoria Nittardi by Tomi Ungerer

Chianti, I was told that they also had problems with labels on wines exported to the United States. In 2007, Tomi Ungerer designed a label that, again, was not allowed (Fig. 3). The sight of naked female bottoms was just too much! Ungerer was 'blacklisted' in the United States, moved to Canada, and then Ireland in 1976, where he died in February 2019 [3]. Incidentally, the vineyard was originally owned by Michelangelo's family and he asked that a case of wine, Nectar Dei, be sent to Pope Julius II in Rome in appreciation of being allowed to fresco the ceiling of the Sistine Chapel (1473-1483). Fattoria Nittardi still sends a case to the Pope and the story was told to us when my wife spotted a letter of gratitude from Pope Benedict XVIth on the wall of the tasting room. The owners of the vineyard, Peter Femfert and his wife Stefania Canali, have commissioned many artists including Yoko Ono, Günter Grass, Dario Fo, and Karl Otto Götz.

So, the cover of a book may have little to do with its contents and the label on a wine bottle, although interesting, does not guarantee its quality. You need to read the book/ journal and drink the wine to judge.

\section{Compliance with ethical standards}

Conflict of interest The author declares that he has no conflict of interest.

Publisher's note: Springer Nature remains neutral with regard to jurisdictional claims in published maps and institutional affiliations.

\section{References}

1. Gale RP. Thirty years of Bone Marrow Transplantation. Bone Marrow Transplant. 2016;51:1411-1142. https://doi.org/10.1038/ bmt2016.175

2. Alice Lascelles. Weekend FT: how to spend it arts edition, The Financial Times Limited, London, UK; 2019.

3. Obituary for Tomi Ungerer, The Irish Times; 2019. 